This is a reviewed article

\title{
The pragmatics of mimesis: A case study of intercultural email communication
}

Liz Marsden ${ }^{1}$ \& Dániel Z. Kádár ${ }^{2}$

Corresponding email: elizabeth.marsden2@hud.ac.uk

\author{
Keywords: \\ mimesis \\ mimicry \\ ritual \\ convention \\ email \\ computer-mediated communication
}

${ }^{1}$ orcid.org/0000-0001-7308-1903

${ }^{2}$ Dániel Kádár's research has been made possible by the MTA Lendület Research Grant (LP2017-5/2017) of the Hungarian Academy of Sciences, which has sponsored $100 \%$ of his time involvement in the present project. 
Abstract

Researchers have pursued interest in how the mimetic practice types of convention and ritual influence the ways in which people build up and maintain interpersonal relationships. Arguably, mimetic interactional acts that animate conventional and ritual practices are key to capturing fundamental aspects of interpersonal phenomena such as politeness, impoliteness, and humour, since language users tend to produce and interpret interpersonal behaviour through normative and repetitive moves, which may develop into routines. Despite the importance of mimetic acts in language use, little research has been done on mimesis itself in the realm of interpersonal pragmatics even though memes themselves have received attention. In this paper, we consider how mimetic chunks of interaction may develop into localised convention and possibly ritual by examining a corpus of 955 business emails between a British sole trader and her international clients, specifically focussing on mimetic practices present in greeting, signing-off and conversation topic. In particular, we attempt to show that by looking into habitual and everyday communication, the origins of conventional and ritual practices may be uncovered. A marked convergence towards using the same greeting or signoff convention is noticeable in our quantitative data analysis and when examining the data qualitatively. The data also show that participants occasionally engage in relational practices that involve repeated and consistent responses to the same stimuli. The results indicate a tendency for accommodative communicative practices to be used, although there is no point at which mimesis can be interpreted as permanently "switched on". 


\section{Introduction}

In this paper, we argue that the current literature on the recurrent interactional phenomena of convention and ritual leaves a gap where the methods of formation of localised convention and ritual are concerned. More specifically, we claim that researchers need to examine the phenomenon of mimesis to be able to answer the question of how conventionalisation and ritualisation operates in interactional communities. While Merlin Donald convincingly argued that mimetic acts play a large part in the formation of such behaviours as ritual, we attempt to provide some data that may show this process in action in natural language. We frame our discussion in terms of Donald's $(1995,2011,2013)$ work on human mimetic skill, Howard Giles' communication accommodation theory (CAT; Dragojevic, Gasiorek, \& Giles, 2016; Gasiorek, 2016; Giles, 2016; Giles, Taylor \& Bourhis, 1973), and Daniel Kádár's (2017) work on conventionalisation and ritualisation.

There is widespread agreement in the field that a large variety of language phenomena, such as indirectness, are conventionalised and/or ritualised (e.g., Tannen, 1981a; Terkourafi, 2001; Terkourafi \& Kádár, 2017). Conventionalisation and ritualisation both reflect and construct the norms of a society or community on the one hand, and, on the other, create moral orders according to which interpersonal behaviour is evaluated (Kádár, 2017). Yet to the best of our knowledge, no previous research has examined mimicking as a trigger for conventionalisation and ritualisation even though several scholars such as Blackmore (2007) and Donald $(1991,2013)$ have convincingly pointed out that ritual is a mimetic phenomenon. According to Donald:

Mimesis ... produces such typically human cognitive patterns as ritual, skill, gesture, tribal identification, personal style, and public spectacle. It explains our irresistible tendency to imitate one another and conform to patterns of group behavior, especially group emotional expression. (Donald, 2011 p. 15)

In other words, while conventionalisation and ritualisation have been studied in the field, these processes represent the long-term product of mimetic behaviour (although "long-term" is a matter of degree, of course), while the pragmatics of mimesis itself has been understudied. Our paper hopes to fill this knowledge gap.

To examine mimetic behaviour in situ, and to show different applications of this practice, we examine three areas of intercultural business email exchanges in this paper: 1) greetings, 2) sign-offs, and 3) conversation topic. Greetings and sign-offs are structural elements contained in the majority of email messages (Cho, 2010); thus, to examine them for imitative practices, we have defined the parameters in which they operate, e.g. for greeting, using "Dear", "Hi", "addressee's name", etc. Having done this, as our data are all from a single email donor (see Gimenez, 2006), we were able to examine the donor's usage of different greeting terms with each email partner for evidence of imitation accommodation in terms of lexical selection (Giles, 2016). For example, if your addressee used "Dear" in their prior email, is it more likely that you will use "Dear" in replying? We hope to go a small way towards addressing this and similar questions.

In our analysis of mimetic behaviour in conversation topic orientation, we looked into participant convergence towards a specific subject or practice which recurs between the participants, such as a recurring complaint or an ongoing joke. Donald (2013) explained reciprocal mimetic games in the following terms: "Someone invents a move; the next one imitates it, and perhaps adds something new. And so on" (p. 189). As these are business emails, mimetic practices will carry across topics such as discussion of deadlines, working practices, and money; however, what interests us are accommodative mimetic moves which occur outside business talk. These conversational elements become part of the ongoing relational work between the participants, but for these to become conventionalised or ritualised, there must be a process of reciprocal mimetic work, as described by Donald (2013) 
above, which embeds this particular "chunk" of relational work in the historical relationship of the conversational partners.

While the examinations of greetings and sign-offs are largely quantitative, with some examples looked at qualitatively in more detail, the analysis of conversation topics is entirely qualitative, studying in detail specific conversational partners' interactional practices. Here we are specifically looking at convergence/divergence (Dragojevic et al., 2016; Giles, 2016) in terms of CAT-that is, email writers choosing to use the same or different forms of greeting/sign-off as their email partner.

Our findings suggest that mimesis is not something that is suddenly in operation, remaining in operation thereafter; rather, there appears to be a phasing in and out of mimetic practice. This is supported by van Baaren et al. (2009):

Research revealed we don't imitate everyone all the time. Our tendency to unconsciously mimic is moderated by both enduring and temporary characteristics of the mimicker and the mimickee. (van Baaren et al., 2009 p. 2382)

This mimetic practice or accommodation towards the conversational partner functioning at some times and not at others has, in the relevant literature, been attributed to a range of factors including in-group/out-group membership (van Baaren et al., 2009), social status/power (Giles, 2016), liking/disliking of the conversational partner (Dragojevic et al., 2016; van Baaren et al., 2009), or even one's ability to produce similar language/behaviour (Dragojevic et al., 2016). Our analysis suggests that, although it is not always in operation, there is a tendency for mimesis (in the form of imitation or convergence) to operate.

Before further discussing how mimetic strategies can be used to create lasting practices, let us first define convention and ritual as two key aspects of interconnectedness in the focus of our study (based on Kádár, 2013; Terkourafi \& Kádár, 2017). Convention and ritual are widely applied concepts in pragmatics, which are often used in interchangeable ways (see more on this problem in Kádár, 2013). Thus, it is useful to attempt to capture the main differences between them. Convention is a recurrent and schematic practice, which comes into existence via conventionalisation (Terkourafi, 2001, 2005). Conventions are normative practices (i.e., they are expected); by acting in conventional ways, interactants conform to contextual expectations and the moral order in a broader sense. Ritual is a recurrent action which reenacts the norms (and associated moral order) of a relational network or broader social group as a "performance" and generates intensive emotions and affection (relational emotions), as Kertzer (1988, p. 67) pointed out. To provide a simple example, singing the national anthem means more to many people than an interactional convention: It has the potential to be a ritual because by singing it, the performers re-enact their national identities (cf. Donald, 2011, p. 15). As with any ritual, this singing event operates with a specific audience, it is noticed, and it occurs in a specific time and space. Conventions can transform into rituals: For instance, a conventional greeting can become an in-group ritual if members of an interactional community playfully repeat it (see Donald, 2013, p. 189)-that is, if it is altered into a situated ritual practice. ${ }^{3}$ The practice of the playful repetition and reinterpretation of a mimetic practice also assumes the operation of "a collective conceptual 'model' of social behavior, expressed in shared ritual and play, and in social structure" (Donald, 2013, p. 189; cf. Haugh, 2010).

The main unresolved issue surrounding conventionalisation and ritualisation is that an interactional practice between two parties does not occur "out of the blue"; rather, it has its origins in mimetic practices: the repeated imitation and elaboration of the behaviours of others (Blackmore, 2007; Donald, 1995, 2011, 2013). When observing interactions, one can see that many types of recurrence cannot be defined as convention or ritual in a narrow sense; we can simply say they are alternative, localised, and temporary conventional practices. These are so different from convention by default that one cannot define them only

\footnotetext{
${ }^{3}$ See Section Mimesis in Conversation Topic for an analysis of this kind of practice between Liz and Zoltan.
} 
as mimetic practice. Looking into mimesis in this respect is valuable because it helps reveal the birth of convention and ritualisation. Additionally, it is valuable to consider this behaviour from the perspective of CAT, which sheds light on the social and personal consequences of such actions.

It is important to point out that convention and ritual are not strictly separable as analytic etic constructs, owing to the fact that whether a practice operates as a convention or a ritual from the participants' point of view depends on individual perceptions of the given practice, the nature of a particular context, and so on. Hence, in this paper, we often refer to the practice types of convention and ritual as "convention/ritual."

This paper will use email data for this discussion, although in future papers, it would be worth using other data types and larger corpora for further testing. Due to limitations on space, this paper cannot explore certain implications of the findings, particularly the social psychology of the pragmatics of mimesis. It seems to be clear to us that through mimetic engagement people create ephemeral moral orders or sets of joint values. Even though the participants of an interaction may not be aware of the exact values of these moral orders, unlike in the case of moral orders evoked by conventional and ritual practices (Kádár, 2017), they may well feel that something has changed when accommodative mimesis sets into motion or ceases to operate. This is an area that we hope to explore in the future.

\section{Data}

The data used for this paper comprise 955 emails collected for the doctoral research of the principal author (Liz Marsden, referred to as "Liz" within the data and our analysis). Marsden collected these emails as she was working as a proofreader and transcriber between 2011 and 2014. All emails in the dataset represent exchanges between her and 12 of her international clients, all of whom are postgraduate or senior researchers who used Marsden's proofreading and/or transcription service while studying at a UK institution. ${ }^{4}$ The length of the email conversations varies from an exchange of 37 emails to an exchange of 147 emails.

Study participants gave their permission to analyse their email data, sensitive and identifying information has been removed, and all participants, with the exception of the principal author, have been anonymised. The data compilation was completed a few months after the start of the first author's PhD project, and the majority of conversations took place before this study was conceptualised; therefore, they represent the author interacting in a natural way without attempting to influence clients as a researcher/ethnographer but simply conducting business. Thus, the statistics presented in this paper represent natural language, not elicited or researcher-influenced conversations. Having argued thus, we are aware that the involvement of analysts in their own data has its limitations. We follow Watts' (1991) example and admit that our data has its limitations due to the unavoidable observer's paradox, which may influence the first author's interpretation of the data.

\footnotetext{
${ }^{4}$ Alice is the only student who was doing solely distance learning; all the others were residents in the UK for all or part of their studies.
} 


\title{
Background
}

Mimesis has been posited as a crucial factor in human evolution, as the transition of a "meme"-"a unit of cultural transmission, or a unit of imitation" (Blackmore 2007, p. 3), allowed ideas to be passed from human to human, enabling the formation of complex thought, theories, rituals, practical knowledge, and much more. As Donald (2011) argued:

Mimesis allowed for the spread of tool-making technology and fire-tending, through imitation and ritual. It also set the stage for the much later evolution of spoken language. (p. 8)

Two examples of memes are shown in the quote above. When many memes form a conglomerate idea, this is known as a "memeplex." Memeplex examples are cultures, religions, and financial institutions which come with their own mimetic "packages" of conventions and rituals.

This ability to imitate allows humans to replicate and repeat observed behaviours (verbal or physical) to form communities and cultures. Practices of interconnectedness-typically, convention and ritual-have their origins here; in this ancient ability to imitate others lies the ability to create practices which have discrete meaning and pass these along. Thus, a group or culture is created that is able to convey complex emotions and practices such as mourning, wedding and wishing luck in conventionalised and ritualised ways, which are instantly understood and accepted by cultural insiders. This idea of insiders is important, as Donald (1995, p. 1094) stated that "learning the mimetic dimensions of another culture is often much more difficult than acquiring the language." Additionally, research by van Baaren et al. (2009) has shown that when out-group members mimic in-group members, those in-group members are likely to like them less, not more. As this paper uses intercultural data, this point ought to be borne in mind throughout the discussion and will be revisited later.

Mimesis is also a key means for situated and social moral orders (Whutnow, 1989) to come into existence:

People have expectations for what constitutes "appropriate" adjustment; according to [CAT], these expectations are grounded in the socio-historical context of a given interaction. (Gasiorek, 2016, pp. 28-29)

\begin{abstract}
"Appropriateness" tends to be evaluated through the lens of the moral orders that interactants inherit through engaging in socialisation, which presumes mimetic engagement. As Donald (1995, p. 1096) noted, "mimetic action must be not only inventive, but also consistent and precise, and thus subject to conscious scrutiny and improvement." Such mimetic engagement is so much a part of people's daily practices that they often do not even notice it (van Baaren et al., 2009), which also explains why the moral orders that we inherit through socialisation are often unnoticed until they get violated (Garfinkel, 1964).

In what follows, we will provide an analysis of how mimesis works in email interaction. The noteworthy feature of email interactions is that in this context, there are no immediate evaluations of the effect of the language used-that is, mimesis operates outside of immediate/spontaneous evaluative moments (Partington, 2007). From the perspective of our analysis, this is an important aspect: Mimesis in such a context is not an immediate reaction, and while one can only speculate about the spontaneity of the interactants' reactions, they can certainly form their messages without time pressure (see an overview of this issue in Frehner, 2008; see also Waldvogel, 2007, p. 458). Therefore, the fact that mimesis nevertheless operates in asynchronous settings provides strong evidence of the power of this phenomenon in interpersonal interaction. In addition, email represents a genre in which conventions are relatively fluid, as Skovholt and Svennevig (2013) found in their analysis of workplace emails:
\end{abstract}


There is great idiosyncratic variation, symptomatic of a system of interaction that is not (yet) strongly codified. This variation may be exploited pragmatically to signal interpersonal relations, and high responsiveness may be used to display involvement and intimacy. (Skovholt and Svennevig, 2013 p. 599)

Furthermore, in our data, the interactions are intercultural in the sense that they take place between Marsden and correspondents from other national cultures. This intercultural background makes conventions even more elusive, as stated earlier. In a sense, while there are certainly pre-existing joint patterns of interaction in such email exchanges, ultimately, the interactants need to work out various conventional practices by exploiting mimesis. This working out of practices of interconnectedness is supposedly valid in any interpersonal interaction, but in the case of intercultural communication via emails, one can suppose that the interactants by default have a certain degree of intercultural awareness that mimetically following each other's practices is a safe way to minimise offence (cf. Blum-Kulka \& Olshtain, 1984). As our analysis illustrates, they not only do this, but they also transform certain conventions into ritual practices.

\section{Analysis}

In the data studied, we captured the operation of mimetic behaviour by focusing on convergence (Dragojevic et al., 2016, p. 37) towards a form of greeting or signing off in emails and by looking at conventionalised ways of responding to particular cues. More specifically, we focused on tendencies for linguistic behaviour to be modified depending on the conversational partner's behaviour. Such responsive behaviour is noteworthy from a relational perspective; it showcases the operation of interconnectedness beyond "strategic" behaviour in a strict sense (Brown \& Levinson, 1987)-that is, as a form of continuous alignment (Watts, 2003) or accommodation (Gasiorek, 2016; Giles, 2016). In a computermediated communication context (particularly in the case of business email; see Zhu, 2003), in which the interactants have limited clues about the other's immediate evaluative moments, adopting the other's conversation topic is a primordial method of alignment, thus coconstructing a locally conventionalised conversation topic. This conventionalised style may transform into ritual if and when the interactants begin to play with it (Donald, 2013, p. 189), such as in the form of jokes (Kádár, 2013), hence transforming it into an in-group performance. As one participant, Liz (the first author), was present throughout all email conversations, it was possible to analyse how her use of certain greeting and sign-off tokens ${ }^{5}$ changed in her conversations with her different clients and whether she developed, or began to develop, conventionalised practices with the other participants.

In what follows, we provide an overview of the various layers of mimetic activity that we observed in our dataset.

\footnotetext{
5 "Token" here refers to individual lexical items.
} 


\section{Mimesis in Greetings}

Table 1 shows the greeting terms used by Liz and the 12 clients across all conversations. The table has six categories, and each of these is explained below with an example from the data (examples show the main body text of the email; subject lines and other metadata are not represented here). Where no ellipsis follows the example text, the text represents the email in full ${ }^{6}$ :

\section{1. "Hi" with or without the addressee's name}

$\mathrm{Hi}, 10$ days is fine, thanks ... [Zoltan: 30] Hi Liz,

I think it would be good I gave it (dictaphone) to you ... [Ruth: 62]

2. "Dear"

Dear Liz

How are you? I am not sure whether you are busy recently, but i need your help ... [Victoria: 26]

3. "Thank*" with or without the addressee's name

Thanks Ploy,

15th December is perfect as one of the big jobs I'm currently doing finishes on the $14^{\text {th }} \ldots$ [Liz to Supaksorn: 13 ]

Thanks,

Are you still intending to send me the rest of your thesis? ... [Liz to Irma: 31]

\section{Emails with no greeting}

I will go to the univ and post it on the research room's board this Friday ... [Supaksorn: 115]

I know, and I had ran out of questions for her ... [Ruth: 95]

\section{Emails using the addressee's name only}

Liz: Just for my part, I can send to you around the end of November ... [Supaksorn: 10]

6. Other greeting forms (including such terms as 'hello', 'sorry', 'ok' etc.) e.g.:

Hello yEa that's okay! Let me know when u r free! ... [Meera: 23]

Sorry Ploy, wrong receipt! [Liz to Supaksorn: 137]

\footnotetext{
${ }^{6}$ Email text is followed by a reference showing the sender (if Liz was the sender, the recipient is also shown) and the email's number in the set collected (e.g., [Liz to Alice: 75] or [Victoria: 3]). All email sets start with [1], this being the email where participants first got in touch or were introduced. N. B. Supaksorn, a client from Thailand, is almost always referred to as "Ploy," her nickname, within emails.Throughout all emails, the original spelling, capitalisation, punctuation, and line splits have been preserved.
} 
In Table 1, the usage of each greeting type is represented by a percentage (for ease of visual comprehension, scores of $50 \%$ and above are in bold, and scores of 0 are left blank). Each conversation is marked using the client's pseudonym, and the percentage of usage for each token in each conversation is listed under either " $C$ " for "client" or " $L$ " for "Liz." The final column shows how many emails were assessed to obtain these percentages. For example, reading left to right, one can see that in Zoltan's conversation with $\mathrm{Liz}$, he used " $\mathrm{Hi}$ " in $83 \%$ of his greetings, while Liz used this term $90 \%$ of the time. They each used "Dear" $10 \%$ and $5 \%$ of the time, respectively.

Table 1. Greeting Terms and Correlation Scores

\begin{tabular}{|c|c|c|c|c|c|c|c|c|c|c|c|c|c|c|}
\hline \multirow{2}{*}{$\begin{array}{l}\begin{array}{l}\text { Greeting } \\
\text { terms } \rightarrow\end{array} \\
\text { Participant } \rightarrow \\
\text { Client } \downarrow\end{array}$} & \multicolumn{2}{|c|}{$\begin{array}{l}\mathrm{Hi}(+/- \\
\text { name) }\end{array}$} & \multicolumn{2}{|l|}{ Dear } & \multicolumn{2}{|c|}{$\begin{array}{l}\text { Thank* (+/- } \\
\text { name) }\end{array}$} & \multicolumn{2}{|c|}{ No greeting } & \multicolumn{2}{|c|}{ Name only } & \multicolumn{2}{|c|}{ Other } & \multicolumn{2}{|c|}{$\begin{array}{l}\text { Total emails } \\
\text { sent }\end{array}$} \\
\hline & C & $\mathrm{L}$ & $\mathrm{C}$ & L & C & L & C & L & $\mathrm{C}$ & L & C & L & $\mathrm{C}$ & $\mathrm{L}$ \\
\hline Alice & & $50 \%$ & $89 \%$ & $48 \%$ & $7 \%$ & $3 \%$ & & & $2 \%$ & & $2 \%$ & & 56 & 40 \\
\hline Avin & $24 \%$ & $81 \%$ & $69 \%$ & $15 \%$ & & & & $4 \%$ & & & $7 \%$ & & 29 & 26 \\
\hline Dana & $\begin{array}{l}80 \\
\%\end{array}$ & $80 \%$ & & $15 \%$ & & $5 \%$ & $20 \%$ & & & & & & 20 & 20 \\
\hline Hai & $\begin{array}{l}65 \\
\%\end{array}$ & $74 \%$ & & $4 \%$ & $13 \%$ & & $26 \%$ & $17 \%$ & & & & & 31 & 23 \\
\hline Hassan & $6 \%$ & $39 \%$ & $71 \%$ & $45 \%$ & $3 \%$ & $6 \%$ & $19 \%$ & $3 \%$ & & $6 \%$ & & & 31 & 31 \\
\hline Imran & $9 \%$ & $77 \%$ & $91 \%$ & $15 \%$ & & & & $8 \%$ & & & & & 34 & 39 \\
\hline Irma & $\begin{array}{l}78 \\
\%\end{array}$ & $89 \%$ & & $5 \%$ & $11 \%$ & $5 \%$ & $6 \%$ & & & & $6 \%$ & & 18 & 19 \\
\hline Meera & $33 \%$ & $70 \%$ & $6 \%$ & $10 \%$ & $17 \%$ & $10 \%$ & $14 \%$ & $7 \%$ & & $3 \%$ & $31 \%$ & & 36 & 30 \\
\hline Supaksorn & $32 \%$ & $87 \%$ & $13 \%$ & $3 \%$ & $4 \%$ & $5 \%$ & $33 \%$ & $1 \%$ & $13 \%$ & & $6 \%$ & & 72 & 75 \\
\hline Ruth & $31 \%$ & $64 \%$ & $10 \%$ & $10 \%$ & $15 \%$ & $5 \%$ & $34 \%$ & $14 \%$ & & $2 \%$ & $11 \%$ & $3 \%$ & 61 & 59 \\
\hline Victoria & $10 \%$ & $45 \%$ & $83 \%$ & $42 \%$ & & $13 \%$ & $7 \%$ & & & & & & 29 & 31 \\
\hline Zoltan & $\begin{array}{l}83 \\
\%\end{array}$ & $90 \%$ & $10 \%$ & $5 \%$ & $5 \%$ & $3 \%$ & $1 \%$ & $2 \%$ & & & $1 \%$ & & 82 & 63 \\
\hline $\begin{array}{l}\text { Total } \\
\text { tokens }\end{array}$ & 187 & 328 & 172 & 75 & 33 & 21 & 72 & 21 & 10 & 4 & 27 & 5 & 499 & 456 \\
\hline Correlation & 0.71 & & 0.77 & & 0.11 & & 0.44 & & -0.18 & & 0.15 & & & \\
\hline
\end{tabular}

Note. The asterisk after "Thank*" indicates that any form of "Thank" may be used (e.g.,

"Thanks" and "Thank you"). Numbers in bold face are those $\geq 50 \%$

The final row of Table 1 contains a correlation score, which for our purposes is essentially an indicator of potential mimetic convergent behaviour. Scores near 0 show that the quantity of each term used varies largely at random. Scores leaning towards +1 show that as each client used the terms more, so did Liz, and vice versa (convergence). Scores towards -1 show that as each client used a term more, Liz used it less, and vice versa (divergence). The positive scores for the "Hi" and "Dear" columns are significant; here convergent mimetic behaviour may be in evidence, as indicated by Liz's alteration of her usage of these greeting terms to suit, to some extent, her clients' preferences. This is examined in more detail below. Before that, the correlation score generation is explained to validate its accuracy.

For these correlations to be accurate, the raw numbers of usage had to be normalised as percentages, thus enabling a like-for-like comparison across different email conversations and making sure correlation results were not skewed by the fact that some conversations 
consisted of more emails than others. ${ }^{7}$ The correlations for three categories, "Hi," "Dear," and "No greeting," show a moderate to high positive correlation. What is particularly interesting here is that this is not simply a result of matching writing styles across the board. ${ }^{8}$ Although Liz generally shows a marked preference for using "Hi" over "Dear," as seen in the " $L$ " columns for these terms, she varies her usage depending on the client's preference, varying from using "Hi" $90 \%$ of the time with Zoltan (whose use is $83 \%$ ) to only $39 \%$ of the time with Hassan (whose use is only 6\%). Similarly, Liz's use of "Dear" varies from $3 \%$ with Ploy (whose use is $13 \%$ ) to $48 \%$ with Alice (whose use is $89 \%$ ). However, the correlation score for "Thank*" shows almost no matching at all (it is close to 0). This could be due to "Thank*" not always being contextually relevant-there must be something to give thanks for, and when "Thank*" is used as a response to another "Thank*," it may appear in the body of the text or in the sign-off rather than in the same sequential position as the initiating email.

What the discussion above indicates is that while writers have their own preferences for language usage, they can vary these to converge towards a conversational partner's practice. The correlation scores for "Hi" and "Dear" are especially interesting, as these terms were used more frequently than other forms of greeting (515 and 247 tokens across all senders, or $54 \%$ and $26 \%$ of total greetings, respectively). Therefore, correlation scores for these terms are more likely to be accurate, as they are based on larger quantities of data (see Table $1 \mathrm{~A}$ in the Appendix for all raw scores). These scores are the most highly positively correlated, indicating a strong chance that mimetic convergent behaviour is in action. Here, whether consciously or unconsciously, the evidence strongly suggests that Liz's greeting token usage changes depending on the conversational partner. Although full convergence is not in evidence (i.e., a complete abandoning of "Hi" in favour of "Dear"), what is evidenced here is partial adjustment-moving towards a co-participant's style, but not completely (Dragojevic et al., 2016, p. 38).

It is difficult to ascertain based on the data above whether clients are adjusting their writing styles. This is because where Liz's usage of different greetings can be shown to change depending on who is the recipient of her emails, for the clients, Liz is always a recipient and no data have been collected where this is not the case. However, when looking at the emails in context or in the order in which they were sent and received, we can see that there may be a move towards mimesis in some conversations. Here we present a set of emails where preferred greeting forms appear to be in opposition: Hassan favours "Dear," while Liz favours "Hi." In the emails below, while mimesis is most often not in operation and participants use their preferred styles regardless of what has happened in the previous email, Hassan and Liz do occasionally deviate from their preferred styles. These instances of deviation (i.e., Hassan using "Hi" or Liz using "Dear") are almost always situated next to another occurrence of that same greeting token, as shown in Table 2.

\footnotetext{
See Table $1 \mathrm{~A}$ in the Appendix.

By which we mean that not all writers exhibit similar preferences.
} 
Table 2. Contextual Mimesis: Liz and Hassan

\begin{tabular}{|c|c|c|c|}
\hline Number & Sender & Type & Greeting \\
\hline 20 & Liz & Reply & Hi Hassan, \\
\hline 21 & Client & Reply & Dear Elizabeth \\
\hline 22 & Liz & Reply & Dear Hassan, \\
\hline 23 & Liz & String & Dear Hassan, \\
\hline 24 & Client & Reply & NO GREETING \\
\hline 25 & Liz & Reply & Hassan \\
\hline 26 & Client & Reply & Dear Elizabeth \\
\hline 27 & Liz & Reply & Hi Hassan, \\
\hline 28 & Client & Reply & Hi Elizabeth \\
\hline 29 & Liz & Reply & Dear Hassan, \\
\hline 30 & Client & Reply & Dear Elizabeth \\
\hline 31 & Liz & Reply & Hi Hassan, \\
\hline 32 & Client & Reply & Dear Elizabeth \\
\hline \multicolumn{4}{|l|}{$\ldots$} \\
\hline 45 & Liz & Reply & Dear Hassan, \\
\hline 46 & Client & Reply & Dear Elizabeth. \\
\hline 47 & Liz & Reply & Hi Hassan, \\
\hline 48 & Client & Reply & Dear Elizabeth \\
\hline 49 & Liz & Reply & Dear Hassan, \\
\hline 50 & Client & Reply & Dear Elizabeth \\
\hline 51 & Liz & Reply & Hi Hassan, \\
\hline 52 & Client & Reply & Dear Elizabeth \\
\hline 53 & Liz & Reply & Dear Hassan, \\
\hline 54 & Client & Reply & Dear Elizabeth \\
\hline 55 & Liz & Reply & Hi Hassan, \\
\hline 56 & Client & Reply & Dear Elizabeth \\
\hline 57 & Liz & Reply & Dear Hassan, \\
\hline
\end{tabular}

Note: boldface shows a greeting different from the sender's norm, italics indicate the email is part of a string of emails from the same sender.

Table 2 shows the greeting tokens used by the two participants. Those in boldface show a different greeting token from the sender's norm. Italics indicate that the email is part of a chain of emails from the same sender; with these "string" emails, it is hard to assess what previous email, ${ }^{9}$ if any, is being responded to. As can be seen above, greeting terms sometimes occur in "clusters," where the greeting used is the same as that of the previous email. However, this pattern is not in operation all the time. Van Baaren et al. (2009) suggested a possible reason for this: "We don't imitate everyone all the time. Our tendency to unconsciously mimic is moderated by both enduring and temporary characteristics of the mimicker and the mimickee" (p. 2382). The authors also suggested that people will try to strike a balance between being distinctive and being accommodative. As Hassan is from a different cultural background (Libya), he may consider "Dear" more appropriate in this context; thus, there may be tension between his desire to accommodate and his desire to uphold his own moral order. Due to space constraints, many of the Hassan/Liz emails are not shown above (1-19, 33-44, 58-62), but the data exhibit a similar pattern, with stretches of different token usage followed by possible mimetic sequences. These convergent sequences are not a one-off occurrence but recur throughout the email conversation. There is no point

\footnotetext{
${ }^{9}$ The current sender's previous email or the other participant's previous email.
} 
where convergence is "switched on" and the participants permanently "decide" to use the same token; for these participants, mimetic practice phases in and out.

Additionally, while some participants such as Zoltan and Liz may be seen to have matching styles (i.e., sharing a preference for "Hi" over "Dear"), this does not presuppose that the strong degree of matching is coincidental; it may be indicative of a high degree of convergence from either or both participants. While it is difficult to test this hypothesis, it is possible to examine instances where either Liz or Zoltan used a greeting form that differed from their personal norm and see if the context gives any clues as to whether this usage was imitative. In this case, the "Dear," "Thank*," and "name only" categories were used sparingly by both participants and are therefore in boldface. Table 3 shows occurrences of these tokens along with the emails that directly preceded and succeeded them.

Table 3. Liz and Zoltan: Non-Typical Greeting Terms

\begin{tabular}{|c|c|c|c|}
\hline $\begin{array}{l}\text { Email } \\
\text { no. }\end{array}$ & Sender & Type & Greeting \\
\hline 38 & Client & Reply & Hi Liz, \\
\hline 39 & Liz & Reply & NO GREETING \\
\hline 40 & Client & Reply & Hi Liz, \\
\hline$\ldots$ & & & \\
\hline 52 & Client & Reply & Hi Liz, \\
\hline 53 & Client & String & NO GREETING \\
\hline 54 & Liz & Reply & Thanks Zoltan \\
\hline 55 & Client & Reply & Thanks Liz \\
\hline 56 & Client & String & Hi Liz, \\
\hline 57 & Client & String & Sorry, Liz, \\
\hline 58 & Liz & Reply & Hi Zoltan, \\
\hline 59 & Client & Reply & Thanks, Liz \\
\hline 60 & Liz & Reply & Hi Zoltan, \\
\hline 61 & Client & Reply & Hi Liz, \\
\hline 62 & Client & String & Dear Liz, \\
\hline 63 & Client & String & Dear Liz, \\
\hline 64 & Liz & Reply & Dear Zoltan \\
\hline 65 & Client & Reply & Dear Liz \\
\hline 66 & Liz & Reply & $\mathrm{Hi}$, \\
\hline 67 & Client & Reply & Dear Liz, \\
\hline 68 & Liz & Reply & Hi Zoltan, \\
\hline
\end{tabular}

\begin{tabular}{|c|c|c|c|}
\hline & & & \\
\hline 71 & Liz & Reply & Hi Zoltan and LJ, \\
\hline 72 & Liz & String & Dear Zoltan and \\
\hline 73 & Client & Reply & Dear Liz, \\
\hline 74 & Liz & Reply & Hi Zoltan, \\
\hline 85 & Client & & \\
\hline 86 & Liz & Reply & Dear Zoltan. \\
\hline 87 & Client & Reply & Dear Liz, \\
\hline 88 & Client & String & Hi Liz, \\
\hline 89 & Liz & Reply & Hi Zoltan, \\
\hline 90 & Client & Reply & Hi Liz, \\
\hline 91 & Liz & Reply & Hi Zoltan, \\
\hline 92 & Client & Reply & Hi Liz, \\
\hline 93 & Liz & Reply & Thanks Zoltan, \\
\hline 94 & Client & Reply & Thanks, Liz, \\
\hline 106 & Client & Reply & Hi Liz, \\
\hline 107 & Client & Reply & Dear Liz, \\
\hline 108 & Liz & Reply & Hi Zoltan, \\
\hline 109 & Client & Reply & Hi Liz, \\
\hline
\end{tabular}

Note: boldface shows a greeting different from the sender's norm, italics indicate the email is part of a string of emails from the same sender.

If nothing other than a coincidental matching of styles was responsible for the high degree of similarity present in the usage of "Hi" versus "Dear" for Liz and Zoltan, one would suppose that non-typical terms would be evenly and randomly spread throughout the data. To put it plainly, if coincidental matching, but not convergence was in play here, one would expect no further indication of mimesis no matter what greeting terms were used, whether preferred or dispreferred. However, Table 3 does show some convergence in action with these dispreferred greetings. Potential mimetic behaviour can be seen in email no. 55; here Zoltan responds to Liz's previous email, which uses "Thanks" as a greeting, by using "Thanks" in his email. The same can be seen in email 64: Liz responds to a duo of "Dear" emails by using "Dear" in her reply. The same happens again in emails 87 and 94 .

To assess whether this pattern was present across the dataset, clients were grouped by whether their preference was "Hi," "Dear," or mixed. Their preference was decided based on whether one greeting term was used $\geq 50 \%$ of the time. Mixed styles had no greeting term 
for which there was a $\geq 50 \%$ usage. To add an extra layer to the intercultural aspect of this analysis, the client's country and first-language background were included (Table 4).

Table 4. Clients' Greeting Preferences and Cultural Backgrounds

\begin{tabular}{|l|l|l|l|l|}
\hline $\begin{array}{l}\text { Greeting } \\
\text { preference }\end{array}$ & Client (gender) & Country of origin & $\begin{array}{l}\text { Broad geographic } \\
\text { region of origin }\end{array}$ & First language \\
\hline \multirow{4}{*}{ "Hi" } & Dana (F) & Slovakia & Central Europe & Slovakian \\
\cline { 2 - 5 } & Hai (M) & China & East Asia & $\begin{array}{l}\text { Mandarin and } \\
\text { Kunming (Chinese) }\end{array}$ \\
\cline { 2 - 5 } & Irma (F) & Cameroon & Central Africa & English \\
\cline { 2 - 5 } & Zoltan (M) & Hungary & Central Europe & Hungarian \\
\hline \multirow{5}{*}{ "Dear" } & Alice (F) & Singapore & Southeast Asia & Hokkien (Chinese) \\
\cline { 2 - 5 } & Avin (F) & Kurdistan & Middle East & Kurdish and Arabic \\
\cline { 2 - 5 } & Hassan (M) & Libya & North Africa & Arabic \\
\cline { 2 - 5 } & Imran (M) & Pakistan & Indian Subcontinent & Pashto \\
\cline { 2 - 5 } & Victoria (F) & China & East Asia & Mandarin (Chinese) \\
\hline \multirow{3}{*}{ Mixed style } & Meera (F) & Pakistan & Indian Subcontinent & Urdu \\
\cline { 2 - 5 } & Ruth (F) & Nigeria & West Africa & Hausa \\
\cline { 2 - 5 } & Supaksorn (F) & Thailand & Southeast Asia & Thai \\
\hline
\end{tabular}

Regarding the intercultural aspect, it is possible to hypothesise (taking Liz's preference into account as well) that the preference for "Hi" is potentially more European. Other styles seem to have no cultural bias, although the mixed style may be more common among female writers. All these hypotheses are pure conjecture given the limited dataset; gathering further sociocultural data, such as the time spent in the British education system, the time spent living in the United Kingdom, and even the desire to adopt UK cultural practices, may illuminate some interesting trends.

For the "Hi" preference, Liz and the clients were seen as having similar styles; therefore, to assess whether mimesis was in play, as with the analysis of Zoltan above, non-typical greetings were examined to see whether they occurred contextually close to other non-typical greetings. In Hai's conversation, a few possibly mimetic clusters of "no greeting" usage were found. For Dana and Irma, the pattern found in Zoltan's data was not present-non-standard greetings were spread evenly throughout both conversations. This could be due to accommodation being only partial, due to participants maintaining their default position without accommodation, or even due to deliberate non-accommodation to a dispreferred greeting form. All these hypotheses are speculative; future studies may gain some insight from post-event interviews, although van Baaren et al. (2009), in their review of mimicking studies, found that many researchers reported that mimicking (or not mimicking) was unconscious and that participants were sometimes surprised by their own behaviour when it was shown to them.

For the "Dear" preference, Liz and the clients were seen as having different styles. Therefore, to assess whether accommodation was in play throughout the email sequence, as with the analysis of Hassan above, dispreferred greetings for each participant were examined to see whether they occurred contextually close to the same greeting token. For Imran, there is a general tendency for similar tokens to be clustered together. In Victoria's data, Liz uses "Dear" much more often than her average usage, leading to sequences of up to 10 emails with the same greeting form. This unusually high usage may be due to a number of socio- 
psychological-cultural factors making Liz want to emphasise closeness/sameness or build rapport (see Donald, 2013; Dragojevic et al., 2016; van Baaren et al., 2009). A similar pattern can be seen in Alice's data, though the sequences tend to be shorter (up to five consecutive emails with the same greeting). Again, as with Victoria, it is Liz making the move towards adopting her client's preferred form. Victoria, on the other hand, rarely uses "Hi," but when she does, it is after an instance of Liz using "Hi." For Avin, there are a few small sequences (2-3 emails) where matching greeting tokens occur, but the usage of dispreferred greeting terms seems largely random.

For mixed greeting users, the data were searched for clusters of any matching tokens. Ruth's and Supaksorn's data showed some short sequences of up to four emails with matching greetings; these were relatively frequent in both datasets, but there were large sequences of non-similar usage. Meera's data, on the other hand, showed only occasional matching pairs. It is possible that with no distinct preference to imitate, Liz was unable to effectively mimic her conversational partners in these settings. It is also possible that clients were, consciously or unconsciously, not converging towards Liz but maintaining their preferred style with no alteration. Table 5. presents a summary of the findings.

Table 5. Summary of Sequences of Identical Greeting Terms

\begin{tabular}{|l|l|l|l|l|l|}
\hline Client & $\begin{array}{l}\text { Client } \\
\text { preference }\end{array}$ & $\begin{array}{l}\text { Liz's usage of } \\
\text { client's } \\
\text { preferred } \\
\text { greeting (\%) }\end{array}$ & $\begin{array}{l}\text { Longest } \\
\text { sequence of } \\
\text { identical } \\
\text { greeting terms }\end{array}$ & $\begin{array}{l}\text { \% of emails in } \\
\text { sequences ( } \geq 3 \\
\text { emails) with } \\
\text { matched } \\
\text { greeting terms }\end{array}$ & $\begin{array}{l}\text { Total emails in } \\
\text { set }\end{array}$ \\
\hline Avin & Dear & $15 \%$ & 4 & $13 \%$ & 55 \\
\hline Meera & Mixed & N/A & 4 & $15 \%$ & 66 \\
\hline Imran & Dear & $15 \%$ & 4 & $26 \%$ & 73 \\
\hline Supaksorn & Mixed & N/A & 6 & $30 \%$ & 147 \\
\hline Ruth & Mixed & N/A & 5 & $33 \%$ & 120 \\
\hline Hassan & Dear & $45 \%$ & 5 & $37 \%$ & 62 \\
\hline Alice & Dear & $48 \%$ & 7 & $38 \%$ & 96 \\
\hline Victoria & Dear & $42 \%$ & 11 & $50 \%$ & 60 \\
\hline Hai & Hi & $74 \%$ & 7 & $59 \%$ & 54 \\
\hline Dana & Hi & $80 \%$ & 12 & $65 \%$ & 40 \\
\hline Irma & Hi & $89 \%$ & $90 \%$ & $83 \%$ & 37 \\
\hline Zoltan & Hi & & & 145 \\
\hline
\end{tabular}

An Assessment of greeting terms only, irrespective of assumed token preference, shows that matched greeting terms occur in at least one cluster of four or more emails in all conversations (see Table 3A in the Appendix). However, as mentioned, where matched styles are present, it is hard to assess whether serendipity or mimetic behaviour is the cause, as there is no way to assess whether clients are converging towards Liz's preference or simply happen to have the same preference themselves.

Yet such similarities become clear as having an accommodative mimetic nature as soon as one examines data like ours by looking into other manifestations of repetitive behaviour. In addition to greeting terms, emails as a format typically contain a sign-off or closing (McKeown \& Zhang, 2015; Waldvogel, 2007). The usage of lexical items in these sign-off phrases will be analysed for convergence in the next section. 


\section{Mimesis in Sign-Offs}

Assessing mimesis in writers' choices of sign-off tokens is more challenging than assessing greetings. While greetings usually consist of one word only (though there is occasional creativity in this regard), sign-offs usually form a phrase of some kind made up of interchangeable parts (e.g., "yours" with or without "faithfully"/"sincerely" and "Best" with or without "wishes"/"regards"). Therefore, in looking for mimetic tendencies, the authors assessed sign-off token usage rather than phrase usage to obtain a manageable and crosscomparable number of categories.

Table 6. Use of Sign-Off Tokens

\begin{tabular}{|c|c|c|c|c|c|c|c|c|c|c|c|c|c|c|c|c|c|c|}
\hline & \multicolumn{2}{|c|}{ "Best" } & \multicolumn{2}{|c|}{ "regards" } & \multicolumn{2}{|c|}{$\begin{array}{c}\text { Sender's } \\
\text { name only }\end{array}$} & \multicolumn{2}{|c|}{ "wishes" } & \multicolumn{2}{|c|}{ "Thank*" } & \multicolumn{2}{|c|}{ Other } & \multicolumn{2}{|c|}{$\begin{array}{c}\text { No sign- } \\
\text { off }\end{array}$} & \multicolumn{2}{|c|}{ "Kind" } & \multicolumn{2}{|c|}{$\begin{array}{c}\text { "Look* } \\
\text { forward" }\end{array}$} \\
\hline & $\begin{array}{l}\stackrel{\cap}{\bar{D}} \\
\stackrel{D}{\partial}\end{array}$ & $\overline{\bar{N}}$ & $\frac{\cap}{\overline{\bar{D}}}$ & $\overline{\bar{N}}$ & $\begin{array}{l}\stackrel{\cap}{\bar{D}} \\
\stackrel{+}{\partial}\end{array}$ & $\overline{\bar{N}}$ & $\begin{array}{l}\stackrel{\cap}{\bar{D}} \\
\stackrel{+}{\partial}\end{array}$ & $\overline{\bar{N}}$ & $\begin{array}{l}\stackrel{\cap}{\bar{D}} \\
\stackrel{+}{\partial}\end{array}$ & $\overline{\bar{N}}$ & 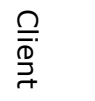 & $\overline{\bar{N}}$ & $\stackrel{\cap}{\stackrel{\cap}{\bar{D}}}$ & $\overline{\bar{N}}$ & $\frac{\Omega}{\overline{\bar{D}}}$ & $\overline{\bar{N}}$ & $\stackrel{\cap}{\stackrel{\cap}{\bar{D}}}$ & $\overline{\bar{N}}$ \\
\hline Alice & $41 \%$ & $75 \%$ & & $25 \%$ & $14 \%$ & $5 \%$ & $39 \%$ & $25 \%$ & $41 \%$ & $3 \%$ & $9 \%$ & $15 \%$ & $4 \%$ & & & & & $3 \%$ \\
\hline Avin & $38 \%$ & $77 \%$ & $62 \%$ & $15 \%$ & $7 \%$ & $8 \%$ & & $4 \%$ & $7 \%$ & & $3 \%$ & $8 \%$ & & & & & & $8 \%$ \\
\hline Dana & $45 \%$ & $\begin{array}{l}100 \\
\% \\
\end{array}$ & & $15 \%$ & $5 \%$ & & $45 \%$ & $5 \%$ & $40 \%$ & & $10 \%$ & & $10 \%$ & & & & & \\
\hline Hai & $\mathbf{5 8} \%$ & $35 \%$ & & & $32 \%$ & $39 \%$ & $\mathbf{5 8} \%$ & $17 \%$ & & & $3 \%$ & $17 \%$ & $10 \%$ & $4 \%$ & & & & \\
\hline Hassan & $16 \%$ & $94 \%$ & & $45 \%$ & $29 \%$ & $6 \%$ & $16 \%$ & $13 \%$ & $3 \%$ & & $32 \%$ & & $19 \%$ & & & & & \\
\hline Imran & $\begin{array}{l}100 \\
\% \\
\end{array}$ & $77 \%$ & $59 \%$ & $18 \%$ & & $8 \%$ & $41 \%$ & & $21 \%$ & $13 \%$ & & $5 \%$ & & & & & & \\
\hline Irma & & $\begin{array}{l}\mathbf{1 0 0} \\
\%\end{array}$ & $89 \%$ & $53 \%$ & & & & & $33 \%$ & & & & & & $89 \%$ & & & \\
\hline Meera & & $33 \%$ & $19 \%$ & $17 \%$ & $36 \%$ & $13 \%$ & & & $11 \%$ & $33 \%$ & $17 \%$ & $13 \%$ & $14 \%$ & $3 \%$ & $11 \%$ & $3 \%$ & & \\
\hline Supaksorn & $1 \%$ & $65 \%$ & $3 \%$ & $1 \%$ & $64 \%$ & $21 \%$ & & $1 \%$ & $10 \%$ & $3 \%$ & $18 \%$ & $8 \%$ & & & & & $3 \%$ & $7 \%$ \\
\hline Ruth & & $63 \%$ & $75 \%$ & $17 \%$ & $2 \%$ & $14 \%$ & & & $10 \%$ & $17 \%$ & $7 \%$ & $3 \%$ & $8 \%$ & & $7 \%$ & & & \\
\hline Victoria & $59 \%$ & $84 \%$ & $3 \%$ & $32 \%$ & & $6 \%$ & $45 \%$ & $13 \%$ & $28 \%$ & $3 \%$ & $7 \%$ & & $7 \%$ & & & & $10 \%$ & $6 \%$ \\
\hline Zoltan & $61 \%$ & $73 \%$ & $6 \%$ & $8 \%$ & $11 \%$ & $8 \%$ & $56 \%$ & $5 \%$ & $28 \%$ & $8 \%$ & $1 \%$ & $5 \%$ & & & & & $1 \%$ & $5 \%$ \\
\hline $\begin{array}{l}\text { Token } \\
\text { total }\end{array}$ & 168 & 324 & 115 & 79 & 99 & 53 & 127 & 28 & 95 & 34 & 45 & 29 & 25 & 2 & & 1 & 6 & 13 \\
\hline $\begin{array}{l}\text { Combined } \\
\text { total }\end{array}$ & 45 & 92 & & & 15 & & & 55 & & & 7 & 4 & 2 & & 25 & & & 9 \\
\hline Correlation & 0. & 08 & & 32 & 0. & & & 53 & & 17 & & 09 & 0. & & 0.0 & & & 50 \\
\hline
\end{tabular}


In Table 6, the usage percentages for each participant across all categories may or may not equal $100 \%$. If someone signed off every email with "Best, [their name]," the score for "Best" would be $100 \%$, while other categories would show "0" (blank). On the other hand, if someone always used "Best regards," both "Best" and "regards" would have scores of $100 \%$. By looking at Table 6 for instances where scores across categories are higher than $100 \%$ for a single participant(e.g. if you add scores for "Best" plus "regards" plus "wishes" and obtain a total greater than $100 \%$ ) it is possible to get an idea of what tokens this participant commonly combines. For example, Irma uses either "Kind regards" (each token at $89 \%$ usage indicates they must often, if not always, co-occur), a phrase containing "Thank*" (33\%), or some combination of the two. In replying to Irma, Liz uses "Best" (100\%, which means this token is always included) or "Best regards" (regards $=53 \%$ ) to sign off.

In Table 6, the correlation scores present some noteworthy results; as a sign-off is more flexible than a greeting, a large number of categories showing no correlation might be expected. However, three categories which each have over 150 total tokens used show a positive correlation-"regards," "name only," and "wishes"10_indicating that participants may be showing mimetic tendencies in their usage of these terms. Nevertheless, the category most used, "Best," has a negligible correlation score. This may indicate that using "Best" is Liz's default position, whatever her addressee is doing, but that she varies what "Best" is combined with (i.e., "regards" or "wishes") based on the client's usage. This gels well with Donald's conception of mimesis, which emphasises that in imitating, the imitator may elaborate upon or creatively alter the source material (Donald, 2011). Additionally, this may be a case of partial adjustment, as described by Dragojevic et al. (2016).

"Thank*," as in the greetings section, shows another negligible correlation score. We posit the same hypothesis for this as in the previous section: The use of "Thank*" must be contextually relevant; thus, it is not always possible to mimic one's writing partner's use of this term. It should be noted, however, that Waldvogel (2007), in her email data, found that in sign-offs:

Sometimes Thanks was used genuinely to express thanks for something done or in anticipation of the meeting of a request, but there were also a number of instances where it was used more as a ritual closing formula" (Waldvogel, 2007 p. 465)

A detailed contextual analysis of "Thank*" usage, which is beyond the scope of this paper, would need to be conducted to ascertain whether this is the case in this dataset.

To illustrate convergence in greeting terms, a good stretch of illustrative behaviour can be found in Zoltan and Liz's early emails to each other. While they use a variety of sign-off terms, these more often than not cluster into pairs or more of similar usage, see Table 7:

\footnotetext{
${ }^{10}$ For raw scores across all sign-off categories for all participants, see Table $2 \mathrm{~A}$ the Appendix.
} 
Table 7. Mimetic Sign-Off Token Usage Between Zoltan and Liz

\begin{tabular}{|c|c|c|c|}
\hline Email no. & Sender & Email type & Sign-off \\
\hline 3 & Client & Reply & $\begin{array}{l}\text { I look forward to collaborating with you. Best wishes, } \\
\text { Zoltan }\end{array}$ \\
\hline 4 & Liz & Reply & $\begin{array}{l}\text { I look forward to working with you, } \\
\text { Liz }\end{array}$ \\
\hline 5 & Client & Reply & $\begin{array}{l}\text { Best, } \\
\text { Zoltan }\end{array}$ \\
\hline 6 & Liz & Reply & $\begin{array}{l}\text { best, } \\
\text { Liz }\end{array}$ \\
\hline 7 & Client & Reply & $\begin{array}{l}\text { All the best, } \\
\text { Zoltan }\end{array}$ \\
\hline 8 & Liz & Reply & $\begin{array}{l}\text { Best regards, } \\
\text { Liz Marsden }\end{array}$ \\
\hline 9 & Client & Reply & $\begin{array}{l}\text { Best regards, } \\
\text { Zoltan }\end{array}$ \\
\hline 10 & Liz & Reply & $\begin{array}{l}\text { Best regards, } \\
\text { Liz Marsden }\end{array}$ \\
\hline 11 & Client & Reply & $\begin{array}{l}\text { Best wishes, } \\
\text { Zoltan }\end{array}$ \\
\hline 12 & Liz & Reply & $\begin{array}{l}\text { All the best, } \\
\text { Liz Marsden }\end{array}$ \\
\hline 13 & Client & Reply & $\begin{array}{l}\text { Many thanks again. } \\
\text { More soon, } \\
\text { Zoltan }\end{array}$ \\
\hline 14 & Client & String & $\begin{array}{l}\text { Thanks in advance. } \\
\text { Regards, } \\
\text { Zoltan }\end{array}$ \\
\hline 15 & Liz & Reply & $\begin{array}{l}\text { all the best, } \\
\text { Liz Marsden }\end{array}$ \\
\hline 16 & Client & Reply & $\begin{array}{l}\text { Best Regards, } \\
\text { Zoltan }\end{array}$ \\
\hline 17 & Liz & Reply & $\begin{array}{l}\text { all the best, } \\
\text { Liz Marsden }\end{array}$ \\
\hline 18 & Client & Reply & $\begin{array}{l}\text { Best Wishes, } \\
\text { Zoltan }\end{array}$ \\
\hline 19 & Liz & Reply & $\begin{array}{l}\text { best wishes, } \\
\text { Liz Marsden }\end{array}$ \\
\hline 20 & Client & Reply & $\begin{array}{l}\text { All the best, } \\
\text { Zoltan }\end{array}$ \\
\hline 21 & Liz & Reply & $\begin{array}{l}\text { All the best, } \\
\text { Liz }\end{array}$ \\
\hline
\end{tabular}

Note: italics indicate that the email is part of a "string" i.e. it is sent after an email from the same sender.

In just 18 emails, there is a large amount of mimicking similar token usage. In the data above, new terms are most often introduced by Zoltan; Liz then mimics these, indicating possible convergent rapport-building behaviour. Our main goal in this paper is to capture mimesis as a phenomenon that is responsible for the operation of the longer-term processes of conventionalisation and ritualisation. What seems to be happening here is that Liz adopts and locally reinterprets what she "inherits" from her writing partner and perceives as social convention to form a localised interactional practice. Such a localised practice may remain a conventional practice of the particular group, and group members may easily deviate from their own conventions-in-formation, as the discussion on the fluctuation of conversation topics makes clear in the next section. Nevertheless, such email conversations illustrate that participants tend to engage in mimetic practices to align with each other. It is also worth noting that such practices may transform into ritual practice (see Introduction), as shown in the following section's analysis of non-serious but varied closings between Liz and Zoltan.

To take a further illustrative example, percentage-wise, Liz's behaviour with Hai looks like divergence in the usage of "Best." Liz deviates from her normal percentage use of this term, moving farther away from Hai's 58\%. However, examined qualitatively, a different story 
emerges, which, like the greeting term analysis, shows clusters of similar usage, illustrating possible convergent behaviour (see Table 4A, Appendix).

Table 8, like Table 5. for greetings, shows sequences of three or more emails within each set which contain at least one matched sign-off token. All tables assessing greetings and signoffs show that Meera seems to have no real preference for how she greets and signs off and that she displays no visible convergence or maintenance. Meera's emails, analysed qualitatively, show many other rapport-enforcing strategies such as humour, complimenting, and thanking, so this pattern may just be a feature of her written idiolect.

Table 8. Summary of Sequences of Identical Sign-Off Terms

\begin{tabular}{|c|c|c|c|}
\hline & $\begin{array}{l}\text { Longest sequence of emails }(\geq 3) \\
\text { using at least one matched sign-off } \\
\text { token }\end{array}$ & $\begin{array}{l}\text { \% of emails in sequences (of three } \\
\text { or more emails) with at least one } \\
\text { matched sign-off token }\end{array}$ & $\begin{array}{l}\text { Total emails } \\
\text { in set }\end{array}$ \\
\hline Meera & 0 & $0 \%$ & 66 \\
\hline Supaksorn & 7 & $8 \%$ & 147 \\
\hline Hassan & 4 & $18 \%$ & 62 \\
\hline Ruth & 6 & $19 \%$ & 120 \\
\hline Alice & 8 & $26 \%$ & 96 \\
\hline Irma & 5 & $38 \%$ & 37 \\
\hline Hai & 4 & $39 \%$ & 54 \\
\hline Victoria & 10 & $40 \%$ & 60 \\
\hline Avin & 4 & $49 \%$ & 55 \\
\hline Dana & 10 & $63 \%$ & 40 \\
\hline Zoltan & 21 & $67 \%$ & 145 \\
\hline Imran & 25 & $79 \%$ & 73 \\
\hline
\end{tabular}

The quantitative analyses put forward so far have shown a tendency for mimesis to operate in such functional areas as email greetings and sign-offs. Now let us look to the main body of the email message to qualitatively analyse mimesis in conversation topics.

\section{Mimesis in Conversation Topic}

As well as presenting quantitative statistics on possible mimetic behaviours, this paper also hopes to present possible evidence of mimetic behaviour in conversation topics. What we mean by this is convergence by participants towards a specific way of responding when a certain subject is mentioned. Of course, to be coherent in one's conversation, one must stay on topic; without a line of argumentation to follow, there would be no coherence and no meaningful transmission from one participant to another. However, what we can examine in this regard are non-salient politeness features which become part of relational work between the participants. For these to become conventionalised or ritualised elements of the ongoing talk, there must be a process of repetition whereby sequences are imitated, elaborated, or played upon (see Donald, 2013, p. 189). Through this repetition, this particular "chunk" of relational work can become embedded in the historical relationship of the conversational partners (Gasiorek, 2016) and be repeated in future talk/writing.

The formation of this kind of relational behaviour is rather like the concept of an adjacency pair in conversation analysis (Levinson, 1983; Schegloff \& Sacks, 1973), a response learned over time-when Speaker says $X$, Hearer should say $Y$. An example is as follows:

\section{A: How are you? \\ B: Fine, thanks.}

This is a simple, conventional social greeting, where "How are you?" is understood to have a different perlocutionary meaning (a "polite" greeting) from its locutionary meaning (a genuine inquiry into the hearer's health). We hypothesise that in repeated sequences in email 
messages, it is possible to see the initial emergence of such a construction on a more localised level. Such a localised construct is not something learned through socialisation, but rather a localised conventional practice between two participants. This can be seen later on in this section in a number of emails where Alice makes repeated self-deprecating references to the quality of her written work. For this to develop into a convention or ritual between participants, both participants must work to create an A/B/A/B pattern by producing similar responses to this subject each time it is mentioned. This sets up a frame or guideline that participants can use in later interactions ${ }^{11}$ :

Mimetic skill, extended to the social realm, results in a collective conceptual "model" of social behavior, expressed in shared ritual and play, and in social structure. (Donald, 2013, p. 189)

Such a form of behaviour has a strong capacity to become ritual instead of simply convention, owing to the fact that the interactants need to exert considerable interactional effort into such forms of alignment activity (Collins, 2005).

The following interaction illustrates the operation of this phenomenon. Here, one such practice that emerges between the two participants in this dataset is Alice's self-deprecating comments about her work, which are followed by praise from Liz.

7. I will send you my draft for Chapter 3 within another 12 hours. This is a "killer chapter" with historical details ... [Alice: 26]

8. I'm looking forward to it :) [Liz to Alice: 27]

9. I hope this chapter will not bore you to tears. I thought the last one would, but your reaction was different ... This chapter is very "dry," so your patience is required (although I lost mine several times). [boldface original, Alice: 36]

10. I'm sure this chapter won't bore me to tears! It's repetition that I find boring, rather than dry facts. Don't worry, I'll take regular breaks from it! [Liz to Alice: 37]

11. I hope this schedule is alright for you. I was less confident about chapters 3 and 4 . The rest of the core chapters are slightly better. So the next two chapters will be slightly easier but not the last, which will be tough to write again. [Alice: 39]

12. I have just finished your fourth chapter - I didn't "die of boredom" (or whatever expression it was that you used!) but it was a tough read for me knowing no Vietnamese it was very hard to remember what you had previously said each term could be used for. [Liz to Alice: 41]

The above excerpts from Liz and Alice's emails show the recurrent mentions of Alice's writing style. In these extracts, Liz repeats Alice's adjectival usage of "dry" and "boring" but improvises around them, at once maintaining the historical link to past emails and doing relational work by showing she has paid close attention to what her conversational partner has said. This sequence may represent an instance of mimesis in conversation topics; in this case, a convention may be emerging in which Alice describes her work negatively and Liz (at least to some extent) refutes those claims. In extract 9, Alice also metapragmatically re-

\footnotetext{
${ }^{11}$ This is common in intimate relationships. Anecdotally, the first author can cite an example of this between her and her partner: It has become a ritual between us to say "Happy tomorrow" to each other if we are both awake as the clock passes midnight. This is clearly not an instance of a culturally dictated ritual, but rather a discrete relational practice which mirrors the New Year's Eve stereotypical celebration convention. Stemming from a unique utterance, through a process of mimesis over many years of cohabiting, this has become a relational ritual firmly embedded in the historicity of our relationship.
} 
enacts Liz's reaction to her previous chapter ("your reaction was different"), perhaps prompting a similar reaction to her following statement. Our dataset illustrates that a) such mimetic moves are regular, and even more importantly, b) once interactants make use of mimesis in conversation topics, such mimetic moves become part of the interactional repertoire of that particular group-that is, this mimetic activity represents an early phase of ritualisation.

An example of this can be seen even more clearly when Zoltan and Liz establish a short ritual around email sign-offs. This case is not presented in the sign-off section, as it does not represent that type of direct imitation, but rather a non-serious convergence. Both participants are mocking or parodying traditional sign-off conventions; thus, this can be seen as mimesis in conversational style (Donald, 2013; Tannen, 1981a, 1981b, 2000). These emails are not part of the PhD dataset, having occurred after data collection was finished, but are used with Zoltan's permission. They therefore have no designation of sequential order for where they occurred in the conversation, but are all at $146+.^{12}$

Initially, Liz questions Zoltan (an academic) about the literature related to a particular term used in her research. Zoltan replies seriously, telling her not to worry and giving her some possible literature sources, and then sends the following string email directly afterwards:

13. Haha, if I wanted to make you frustrated I would add: Liz, why are you not using Best Wishes in your e-mail? Is it conscious?

Just kidding, and forget about the observer paradox thing.

Z.

In the above email, Zoltan deliberately teases Liz, making her acutely self-aware of her signoff practices. Hence, in her next email, although the main body text is about her ethics process for her PhD, she signs off as follows:

\section{Best wishes $(: P)$}

Liz

The tongue-out emoticon is indicative of a non-serious attitude (Skovholt, Grønning, \& Kankaanranta, 2014), though interestingly, the use of parentheses perhaps indicates that this bit of relational work is distanced from the overall seriousness of her message. In the next few emails, the sign-offs are as follows:

15. With very best wishes $((((($ :

Zoltan

16. Best wishes!

Liz

Best best wishes! Yours Sincerely! Sincerely Yours! Faithfully! Etc. etc.

Zoltan

17. With much seasonal good cheer, ${ }^{13}$

Liz

\footnotetext{
12 Zoltan's dataset contains 145 emails, and these all occur after the $145^{\text {th }}$ email.

${ }^{13}$ Email sent on 15 December 2014.
} 
18. Sincerely from thy humble [identifying information omitted], Zoltan

19. See you tomorrow, Liz

20. With Good Wishes for Christmas, Zoltan

With the exception of (20), which seems to be a relatively normal sign-off, all the above follow a pattern of each responding to the other with a non-serious sign-off despite the comparatively serious topic of the email body text. For example, the text of email 15 reads as follows:

Good job. Shall we meet on Wednesday, around 3-ish? [identifying information omitted]

On the basis of my first very quick look, I could find no self-foot-shooting in the document, but if you feel concerned about any particular issue please describe it, in order for me to think about it.

This email seems business-like, albeit with some more "conversational" features (e.g., "ish" and "self-foot-shooting"), as often described in email data (Cho, 2010; Gains, 1999; Gordon \& Luke, 2012; Herring, 2001). Here we have an instance of mimetic convergent behaviour which is beginning to look ritualised; it only occurs in specific contexts (sign-offs), it is repeated, and outsiders may not recognise its salience-although it could look odd, as many rituals do from the outside! However, this ritual only lasts for these emails shown above ${ }^{14}$; after this period, both participants take an extended break for the Christmas holiday, and on their return, resume their typical pre-ritual signing-off practices.

As another example of mimesis emerging from a particular orientation to a topic, the following case is pertinent. In the following conversation with Ruth, a new interactional practice emerges just after a troublesome sequence between the participants. The problem, in brief, was that Ruth sent Liz work to proofread that was significantly longer than she had previously stated. Liz said she could not read so much in a short time, and then left the house and remained away from her email for several hours. During this time, Ruth sent three increasingly anxious emails asking her to respond. Eventually, when Liz returned home and responded, an agreement was reached for Liz to do as much work as possible in the available time. After sending this completed work to Ruth, two days later, Liz sent the following email relating to a transcription she had done for Ruth, which was part of an ongoing job of several audio transcriptions that overlapped the proofreading work:

\footnotetext{
${ }^{14}$ See van Baaren et al. (2009) for a discussion of how mimicking can be turned on and off, and Dragojevic et al. (2016, p. 39) for a discussion of short-term adjustment.
} 
21. Hi Ruth,

Here is Agnes's transcript, the end of her interview made me laugh - I don't think she wanted you to stop!

Best regards,

Liz [Liz to Ruth: 94]

Previously, Liz had simply attached the transcription to an email and stated which participant in Ruth's study the transcript belonged to, so this represents a departure from her previously established practice. The extra detail shown could have been added due to the mentioned context and might be an attempt at some relational repair work after the troublesome sequence. Ruth responded to this email as follows:

22. I know, and I had ran out of questions for her ... Guess what she never wanted to take initially - as didn't know I wasn't interested in personal details, and it turned out that she never wanted it to stop.

Thanks again Liz.

Ruth [Ruth: 95]

This favourable response leads to the establishing of a new interactional practice; from then on, when Liz returned transcripts, she usually added some note about the participant (below are excerpts, not entire emails):

23. Here's Gemma,

I enjoyed her interview, she's funny! There's a lot of what linguists call 'smile voice' in her transcript (saying things with a smile/slight laugh behind them). [Liz to Ruth: 99]

24. Thank you! I'm learning from you too as I've never heard of that before. But was very lay back and wanted to leave - she was my very first as well, had not gained enough interviewing skills then. But hopes it was ok. [Ruth: 100]

25. I think Emma was the most confident speaker you've interviewed, there were hardly any pauses in her transcript at all, and she's a fast talker ... I can tell you that the fastest speaker so far has been Emma at 180 words per minute, the slowest was Agnes at 164 - which really shows a big variance; that's why it's so hard to give price estimates for transcripts! [Liz to Ruth: 101]

26. Thank you Liz. That's why I'm happy for you to do my transcribing and other jobs for me. [Ruth: 102]

This kind of added relational work, which takes place alongside business, as in the other examples above (7-21) is where these kinds of relational conventions and/or rituals have a chance to develop. Like Alice's mention of Liz's prior reaction to her work, Ruth encourages this practice to continue in excerpt 25: "I'm learning from you too as I've never heard of that before." These practices have the chance to recur and therefore become embedded in the participants' relational history if participants work together to maintain them. The establishment of these practices as an interpersonal ritual is dependent on the relationship continuing, and in Ruth's case, on the continued need to produce transcriptions. In this particular case, Ruth soon states she has insufficient funds for the transcriptions to continue, so this practice barely has a chance to get going before it no longer has a reason to function. This parallels how some rituals can be situated in a specific time and context, ceasing to exist 
once the need for them has passed (see Kádár, 2013, 2017 for examples of this in face-toface interaction).

In all cases in this dataset, the business relationship has something of an "expiration date"; when the work is completed, there ceases to be a reason to interact. Therefore, not only due to the limited contact period, but also because these relationships exist primarily for functional rather than friendship reasons, these recurrences can only be seen to show potential development lines of regularities, temporary mimetic in-group conventions/rituals, or shortlived communication accommodation. In future research, it would be worth searching for mimetic/accommodative practices such as these in emails between long-standing colleagues, friends, or relatives, where the practice has adequate time to develop and perhaps to evolve. This would, in turn, help us in attempting to interconnect accommodative mimesis with the phenomena of conventionalisation and ritualisation.

\section{Conclusion}

By looking into convergent and accommodative mimetic moves in various units of analysis in our dataset, we hope to have demonstrated that accommodative mimesis represents how conventionalisation and ritualisation are set into action in the lives of communities of practice (Davies, 2005). Such ephemeral moves towards conventionalisation and ritualisation differ from a) actual conventionalisation and ritualisation, which produce long-lasting interactional practices, and b) accommodative moves in socially established practice types. Here we need to revisit the fact that the phenomena that we have studied represent ephemeral behavioural rudiments which come and go. These rudiments do not exist in a vacuum: They reflect what interactants may perceive as appropriate based on a particular relational history; but at the same time, the interactants who engage in such mimetic moves are in the process of accommodation and, as such, cannot necessarily follow social routines, which would be available in less ambiguous settings. Thus, accommodative moves-the ephemeral rudiments of convention and ritual-differ from the routinised practices of convention and ritual, which societies develop over relatively long periods. Once such practices come into existence, they are not only resistant to changes, but also become incorporated into the habitus of language users through socialisation.

In our dataset, mimicking/convergence may or may not be in operation within each email conversation, although as shown in the correlation scores for greeting and sign-off tokens, there is certainly a tendency for it to operate in these areas. A marked convergence towards using the same greeting or sign-off convention is noticeable in the usage percentages and when examining the data of participants in context. The data also show that participants occasionally engage in relational practices that involve repeated and consistent responses to the same stimuli-for example, providing unsolicited information that triggers a positive response, or a non-serious sign-off being followed by another non-serious sign-off. Given sufficient time and a consistent need or desire for the participants to interact, these mimetic practices can develop into in-group conventions or rituals. 


\section{References}

Blackmore, S. (2006). It is possible to live happily and morally without believing in free will. In J. Brockman (Ed.), What we believe but cannot prove: Today's leading thinkers on science in the age of certainty (pp. 41-42). London, England: Free Press.

Blackmore, S. (2007). Imitation makes us human. In C. Pasternak (Ed.), What makes us human? (pp. 1-16). Oxford, UK: Oneworld.

Blum-Kulka, S., \& Olshtain, E. (1984). Requests and apologies: A cross-cultural study of speech act realization patterns (CCSARP). Applied Linguistics, 5(3), 196-213. https://doi.org/10.1093/applin/5.3.196

Brown, P., \& Levinson, S. C. (1987). Politeness, some universals in language usage. Cambridge, UK: Cambridge University Press.

Chen, X. (2017). Extensions of the Chinese passive construction: A memetic account. East Asian Pragmatics, 2(1), 59-74. https://doi.org/10.1558/eap.32412

Cho, T. (2010). Linguistic features of electronic mail in the workplace: A comparison with memoranda. Language@Internet, 7, 1-28.

Collins, R. (2005). Interaction ritual chains. Princeton, NJ: Princeton University Press.

Davies, B. L. (2005). Communities of practice: Legitimacy not choice. Journal of Sociolinguistics, 9, 557-581. https://doi.org/10.1111/j.1360-6441.2005.00306.x

Donald, M. (1991). Origins of the modern mind. Cambridge, MA: Harvard University Press.

Donald, M. (1995). The neurobiology of human consciousness: An evolutionary approach. Neuropsychologia, 33(9), 1087-1102. doi:10.1016/0028-3932(95)00050-D https://doi.org/10.1016/0028-3932(95)00050-D

Donald, M. (2011). Art and cognitive evolution. In M. Turner (Ed.), The artful mind: Cognitive science and the riddle of human creativity (pp. 3-20). New York, NY: Oxford University Press. https://doi.org/10.1093/acprof:oso/9780195306361.003.0001

Donald, M. (2013). Mimesis theory re-examined, twenty years after the fact. In H. Pittman \& G. Hatfield (Eds.), Evolution of mind, brain and culture (pp. 169-192). Philadelphia, PA: University of Pennsylvania Press. https://doi.org/10.9783/9781934536605.169

Dragojevic, M., Gasiorek, J., \& Giles, H. (2016). Accommodative strategies as core of the theory. In H. Giles (Ed.), Communication accommodation theory: Negotiating personal relationships and social identities across contexts (pp. 36-59). Cambridge, UK: Cambridge University Press. https://doi.org/10.1017/CB09781316226537.003

Frehner, C. (2008). Email, SMS, MMS: The linguistic creativity of asynchronous discourse in the new media age. Bern, Switzerland: Peter Lang.

Gains, J. (1999). Electronic mail-a new style of communication or just a new medium? An investigation into the text features of e-mail. English for Specific Purposes, 18(1), 81101. https://doi.org/10.1016/S0889-4906(97)00051-3

Garfinkel, H. (1964). Studies of the routine grounds of everyday activities. Social Problems, 11(3), 225-250. doi: $10.2307 / 798722$ https://doi.org/10.2307/798722

Gasiorek, J. (2016). Theoretical perspectives on interpersonal adjustments in language and communication. In H. Giles (Ed.), Communication accommodation theory: Negotiating personal relationships and social identities across contexts (pp. 13-35). Cambridge, UK: Cambridge University Press. https://doi.org/10.1017/CB09781316226537.002 
Giles, H. (2016). The social origins of CAT. In H. Giles (Ed.), Communication accommodation theory: Negotiating personal relationships and social identities across contexts (pp. 1-12). Cambridge, UK: Cambridge University Press. https://doi.org/10.1017/CB09781316226537.001 https://doi.org/10.1017/CBO9781316226537

Giles, H., Taylor, D. M., \& Bourhis, R. (1973). Towards a theory of interpersonal accommodation through language: Some Canadian data. Language in Society, 2(2), 177-192. https://doi.org/10.1017/S0047404500000701

Gimenez, J. C. (2006). Embedded business emails: Meeting new demands in international business communication. English for Specific Purposes, 25, 154-172. https://doi.org/10.1016/j.esp.2005.04.005

Gordon, C., \& Luke, M. (2012). Discursive negotiation of face via email: Professional identity development in school counseling supervision. Linguistics and Education, 23(1), 112-122. https://doi.org/10.1016/j.linged.2011.05.002

Haugh, M. (2010). Jocular mockery, (dis)affiliation and face. Journal of Pragmatics, 42(8), 2106-2119. https://doi.org/10.1016/j.pragma.2009.12.018

Herring, S. (2001). Computer-mediated discourse. In D. Schiffrin, D. Tannen, \& H. Hamilton (Eds.), The handbook of discourse analysis. Oxford, UK: Oxford Blackwell.

Kádár, D. Z. (2013). Relational rituals and communication: Ritual interaction in groups. London, England: Palgrave Macmillan. https://doi.org/10.1057/9780230393059

Kádár, D. Z. (2017). Politeness, impoliteness, and ritual: Maintaining the moral order in interpersonal interaction. Cambridge, UK: Cambridge University Press. https://doi.org/10.1017/9781107280465

Kertzer, D. I. (1988). Ritual, Politics, and Power. New Haven, CT: Yale University Press Levinson, S. C. (1983). Pragmatics. Cambridge, UK: Cambridge University Press.

McKeown, J., \& Zhang, Q. (2015). Socio-pragmatic influence on opening salutation and closing valediction of British workplace email. Journal of Pragmatics, 85, 92-107. https://doi.org/10.1016/j.pragma.2015.06.012

O'Driscoll, J. (2011). Some issues with the concept of face: When, what, how and how much? In F. Bargiela-Chiappini \& D. Z. Kádár (Eds.), Politeness across cultures (pp. 17-41). Basingstoke, England: Palgrave Macmillan. https://doi.org/10.1057/9780230305939 2

Partington, A. (2007). Irony and reversal of evaluation. Journal of Pragmatics, 39, 15471569. https://doi.org/10.1016/j.pragma.2007.04.009

Schegloff, E., \& Sacks, H. (1973). Opening up closings. Semiotica, 7(4), 289-327. https://doi.org/10.1515/semi.1973.8.4.289

Skovholt, K., Grønning, A., \& Kankaanranta, A. (2014). The communicative functions of emoticons in workplace e-mails: :- $)_{*}$. Journal of Computer-Mediated Communication, 19(4), 780-797. https://doi.org/10.1111/jcc4.12063

Skovholt, K., \& Svennevig, J. (2013). Responses and non-responses in workplace emails. In S. C. Herring, D. Stein, \& T. Virtanen (Eds.), Handbook of pragmatics of computermediated communication (pp. 581-603). Berlin, Germany: Mouton. https://doi.org/10.1515/9783110214468.589

Tannen, D. (1981a). Indirectness in discourse: Ethnicity as conversational style. Discourse Processes, 4(3), 221-238. https://doi.org/10.1080/01638538109544517 
Tannen, D. (1981b). The machine-gun question: An example of conversational style. Journal of Pragmatics, 5, 383-397. https://doi.org/10.1016/0378-2166(81)90025-4

Tannen, D. (2000). "Don't just sit there--interrupt!" Pacing and pausing in conversational style. American Speech, 75(4), 393-395. https://doi.org/10.1215/00031283-75-4-393

Terkourafi, M. (2001). Politeness in Cypriot Greek: A frame-based approach (Unpublished doctoral thesis). University of Cambridge, England.

Terkourafi, M. (2005). Beyond the micro-level in politeness research. Journal of Politeness, $1(2), 237-262$. https://doi.org/10.1515/jplr.2005.1.2.237

Terkourafi, M., \& Kádár, D. Z. (2017). Convention and ritual. In J. Culpeper, M. Haugh, \& D. Z. Kádár (Eds.), The Palgrave handbook of linguistic (im)politeness (pp. 171-195). Basingstoke, England: Palgrave Macmillan. https://doi.org/10.1057/978-1-137-37508-7_8

van Baaren, R., Janssen, L., Chartrand, T. L., \& Dijksterhuis, A. (2009). Where is the love? The social aspects of mimicry. Philosophical Transactions of the Royal Society of London. Series B, Biological Sciences, 364, 2381-2389. https://doi.org/10.1098/rstb.2009.0057

Waldvogel, J. (2007). Greetings and closings in workplace email. Journal of ComputerMediated Communication, 12(2), 122-143. https://doi.org/10.1111/j.1083-6101.2007.00333.x

Watts, R. J. (1991). Power in family discourse. Berlin, Germany: Mouton de Gruyter. https://doi.org/10.1515/9783110854787

Watts, R. J. (2003). Politeness. Cambridge, UK: Cambridge University Press. https://doi.org/10.1017/CBO9780511615184

Whutnow, R. (1989). Meaning and moral order: Explorations in cultural analysis. Berkeley, CA: University of California Press.

Zhu, Y. (2003). Written communication across cultures. Amsterdam, Netherlands: John Benjamins. 


\section{Appendix}

Table 1A. Raw Data Showing Usage of Greeting Tokens

\begin{tabular}{|c|c|c|c|c|c|c|c|c|c|c|c|c|c|c|}
\hline & \multicolumn{2}{|c|}{$\begin{array}{l}\mathrm{Hi}(+/- \\
\text { name) }\end{array}$} & \multicolumn{2}{|c|}{$\begin{array}{l}\text { Dear }(+/- \\
\text { name) }\end{array}$} & \multicolumn{2}{|c|}{$\begin{array}{l}\text { Thanks (+/- } \\
\text { name) }\end{array}$} & \multicolumn{2}{|c|}{ No greeting } & \multicolumn{2}{|c|}{ Name only } & \multicolumn{2}{|c|}{ Other } & \multicolumn{2}{|c|}{$\begin{array}{l}\text { Total emails } \\
\text { sent }\end{array}$} \\
\hline & $\mathrm{C}$ & $\mathrm{L}$ & $\mathrm{C}$ & $\mathrm{L}$ & $C$ & $\mathrm{~L}$ & $C$ & $\mathrm{~L}$ & $C$ & $\mathrm{~L}$ & $C$ & $\mathrm{~L}$ & $\mathrm{C}$ & $\mathrm{L}$ \\
\hline Alice & 0 & 20 & 50 & 19 & 4 & 1 & 0 & 0 & 1 & 0 & 1 & 0 & 56 & 40 \\
\hline Avin & 7 & 21 & 20 & 4 & 0 & 0 & 0 & 1 & 0 & 0 & 2 & 0 & 29 & 26 \\
\hline Dana & 16 & 16 & 0 & 3 & 0 & 1 & 4 & 0 & 0 & 0 & 0 & 0 & 20 & 20 \\
\hline Hai & 20 & 17 & 0 & 1 & 4 & 0 & 8 & 4 & 0 & 0 & 0 & 0 & 31 & 23 \\
\hline Hassan & 2 & 12 & 22 & 14 & 1 & 2 & 6 & 1 & 0 & 2 & 0 & 0 & 31 & 31 \\
\hline Imran & 3 & 30 & 31 & 6 & 0 & 0 & 0 & 3 & 0 & 0 & 0 & 0 & 34 & 39 \\
\hline Irma & 14 & 17 & 0 & 1 & 2 & 1 & 1 & 0 & 0 & 0 & 1 & 0 & 18 & 19 \\
\hline Meera & 12 & 21 & 2 & 3 & 6 & 3 & 5 & 2 & 0 & 1 & 11 & 0 & 36 & 30 \\
\hline Ploy & 23 & 65 & 9 & 2 & 3 & 4 & 24 & 1 & 9 & 0 & 4 & 3 & 72 & 75 \\
\hline Ruth & 19 & 38 & 6 & 6 & 9 & 3 & 21 & 8 & 0 & 1 & 7 & 2 & 61 & 59 \\
\hline Victoria & 3 & 14 & 24 & 13 & 0 & 4 & 2 & 0 & 0 & 0 & 0 & 0 & 29 & 31 \\
\hline Zoltan & 68 & 57 & 8 & 3 & 4 & 2 & 1 & 1 & 0 & 0 & 1 & 0 & 82 & 63 \\
\hline Total & 187 & 328 & 172 & 75 & 33 & 21 & 72 & 21 & 10 & 4 & 27 & 5 & 499 & 456 \\
\hline
\end{tabular}

Note: "C" and "L" refer to "client" and "Liz"

Table 2A. Raw Data Showing Usage of Sign-Off Tokens

\begin{tabular}{|c|c|c|c|c|c|c|c|c|c|c|c|c|c|c|c|c|c|c|c|c|}
\hline & \multicolumn{2}{|c|}{ Person } & \multicolumn{2}{|c|}{ "Best" } & \multicolumn{2}{|c|}{ "regards" } & \multicolumn{2}{|c|}{$\begin{array}{l}\text { Name } \\
\text { only }\end{array}$} & \multicolumn{2}{|c|}{$\begin{array}{l}\text { "wishes } \\
\text { " }\end{array}$} & \multicolumn{2}{|c|}{$\begin{array}{l}\text { "Thank } \\
\text { *" }\end{array}$} & \multicolumn{2}{|c|}{ Other } & \multicolumn{2}{|c|}{$\begin{array}{l}\text { No } \\
\text { sign-off }\end{array}$} & \multicolumn{2}{|c|}{ "Kind" } & \multicolumn{2}{|c|}{$\begin{array}{l}\text { "Look* } \\
\text { forward" }\end{array}$} \\
\hline & $C$ & $L$ & C & $\mathrm{L}$ & $\mathrm{C}$ & $L$ & $\mathrm{C}$ & $\mathrm{L}$ & $\mathrm{C}$ & $\mathrm{L}$ & $\mathrm{C}$ & $\mathrm{L}$ & $\mathrm{C}$ & $\mathrm{L}$ & $\mathrm{C}$ & $\mathrm{L}$ & $\mathrm{C}$ & $\mathrm{L}$ & $\mathrm{C}$ & $\mathrm{L}$ \\
\hline Alice & 12 & 11 & & & 4 & 2 & 12 & 7 & 9 & 1 & 4 & 5 & 1 & & & & & 1 & 28 & 20 \\
\hline Avin & 9 & 11 & 6 & & & & & & 2 & & 1 & 1 & & & & & & 1 & 15 & 13 \\
\hline Dana & 5 & 11 & & 2 & & & 5 & 1 & 3 & & 1 & & 1 & & & & & & 9 & 11 \\
\hline Hai & 8 & 7 & & & 6 & 3 & 8 & 3 & & & & 3 & & & & & & & 14 & 13 \\
\hline Hassan & 2 & 14 & & 8 & 5 & 2 & 2 & 3 & 1 & & 4 & & 3 & & & & & & 15 & 16 \\
\hline Imran & 17 & 16 & 5 & 3 & & 2 & 12 & 2 & 4 & 1 & & 2 & & & & & & & 17 & 20 \\
\hline Irma & & 13 & 7 & 5 & & & & & & & & & & & 7 & & & & 7 & 13 \\
\hline Meera & & 8 & 4 & 3 & 5 & 1 & & & & 4 & 3 & 3 & 5 & & 1 & & & & 17 & 16 \\
\hline Ploy & 1 & 21 & 2 & & 24 & 14 & & 1 & 2 & & 2 & 5 & 1 & & & & 1 & 2 & 33 & 41 \\
\hline Ruth & & 22 & $\begin{array}{l}1 \\
9\end{array}$ & 9 & & 5 & & & 3 & 3 & 1 & 1 & 3 & & 2 & & & & 28 & 32 \\
\hline Victoria & 5 & 15 & & 4 & & & 4 & 3 & 4 & 1 & 2 & & 2 & & & & 1 & & 14 & 16 \\
\hline Zoltan & 31 & 24 & 2 & 3 & 3 & 2 & 25 & 2 & 13 & 2 & 1 & 2 & & & & & & 1 & 42 & 31 \\
\hline Total & 90 & $\begin{array}{l}17 \\
3\end{array}$ & $\begin{array}{l}4 \\
5\end{array}$ & $\begin{array}{l}3 \\
7\end{array}$ & 47 & 31 & 68 & 22 & 41 & 12 & 19 & 22 & 16 & 0 & 10 & 0 & 2 & 5 & $\begin{array}{l}23 \\
9\end{array}$ & $\begin{array}{l}24 \\
2\end{array}$ \\
\hline
\end{tabular}

Note: "C" and "L" refer to "client" and "Liz" 


\section{FLEKS}

Table 3A. Length of Identical Greeting Sequences

\begin{tabular}{|c|c|c|c|c|c|c|c|c|c|c|c|c|c|c|c|c|c|c|c|c|c|c|c|}
\hline \multicolumn{20}{|c|}{ Strings of same greetings ( 2 strings included) in order of occurrence } & \multirow{2}{*}{$\begin{array}{l}\begin{array}{l}\text { Aver } \\
\text { age }\end{array} \\
8.80\end{array}$} & \multirow{2}{*}{$\begin{array}{l}\begin{array}{l}\text { Sent } \\
\text { email } \\
\text { s }\end{array} \\
145\end{array}$} & \multirow{2}{*}{$\begin{array}{l}\text { \% with } \\
\text { same } \\
\text { greetin } \\
\text { g } \\
91 \%\end{array}$} & \multirow{2}{*}{$\begin{array}{l}\text { Style } \\
\mathrm{Hi}\end{array}$} \\
\hline Zoltan & 38 & 12 & 2 & 2 & 4 & 3 & 2 & 12 & 2 & 5 & 2 & 3 & 8 & 2 & 35 & & & & & & & & \\
\hline Irma & 8 & 6 & 10 & 3 & 3 & 2 & & & & & & & & & & & & & & 5.33 & 37 & $86 \%$ & $\mathrm{Hi}$ \\
\hline Dana & 12 & 2 & 10 & 4 & 2 & & & & & & & & & & & & & & & 6.00 & 40 & $75 \%$ & $\mathrm{Hi}$ \\
\hline Hai & 7 & 2 & 6 & 4 & 3 & 6 & 6 & & & & & & & & & & & & & 4.86 & 54 & $63 \%$ & $\mathrm{Hi}$ \\
\hline Victoria & 7 & 11 & 4 & 5 & 3 & & & & & & & & & & & & & & & 6.00 & 60 & $50 \%$ & Dear \\
\hline Hassan & 3 & 5 & 3 & 2 & 2 & 3 & 2 & 3 & 3 & 3 & & & & & & & & & & 2.90 & 62 & $47 \%$ & Dear \\
\hline Ruth & 4 & 3 & 3 & 3 & 5 & 2 & 3 & 3 & 5 & 2 & 2 & 3 & 4 & 2 & 2 & 2 & 2 & 2 & 3 & 2.89 & 120 & $46 \%$ & Mixed \\
\hline Alice & 3 & 6 & 2 & 3 & 3 & 3 & 2 & 7 & 3 & 2 & 3 & 5 & 2 & & & & & & & 3.38 & 96 & $46 \%$ & Dear \\
\hline Supaksorn & 2 & 6 & 2 & 5 & 4 & 3 & 2 & 6 & 6 & 2 & 3 & 2 & 3 & 3 & 2 & 2 & 2 & 5 & & 3.33 & 147 & $41 \%$ & Mixed \\
\hline Avin & 2 & 2 & 2 & 3 & 2 & 2 & 4 & 2 & & & & & & & & & & & & 2.38 & 55 & $35 \%$ & Dear \\
\hline Imran & 3 & 3 & 2 & 3 & 3 & 3 & 4 & & & & & & & & & & & & & 3.00 & 73 & $29 \%$ & Dear \\
\hline Meera & 3 & 2 & 3 & 2 & 2 & 4 & 2 & & & & & & & & & & & & & 2.57 & 66 & $27 \%$ & Mixed \\
\hline
\end{tabular}


Table 4A. Sign-Offs of Hai and Liz: All Emails

\begin{tabular}{|c|c|c|c|}
\hline 2 & Client & Reply & $\begin{array}{l}\text { Best wishes, } \\
\text { Hai }\end{array}$ \\
\hline 3 & Client & String & NO SIGN-OFF \\
\hline 4 & Client & String & $\begin{array}{l}\text { Best wishes, } \\
\mathrm{Hai}\end{array}$ \\
\hline 5 & Client & String & $\begin{array}{l}\text { Best wishes, } \\
\text { Hai }\end{array}$ \\
\hline 6 & Client & String & $\begin{array}{l}\text { Best wishes, } \\
\text { Hai }\end{array}$ \\
\hline 7 & Liz & Reply & $\begin{array}{l}\text { Best wishes, } \\
\text { Liz }\end{array}$ \\
\hline 8 & Client & Reply & $\begin{array}{l}\text { Best wishes, } \\
\text { Hai }\end{array}$ \\
\hline 9 & Liz & Reply & Liz \\
\hline 10 & Client & Reply & Hai \\
\hline 11 & Client & String & $\begin{array}{l}\text { Best wishes, } \\
\mathrm{Hai}\end{array}$ \\
\hline 12 & Liz & Reply & Liz \\
\hline 13 & Client & Reply & $\begin{array}{l}\text { Best wishes, } \\
\text { Hai }\end{array}$ \\
\hline 14 & Client & String & $\begin{array}{l}\text { Best wishes, } \\
\mathrm{Hai}\end{array}$ \\
\hline 15 & $\overline{\mathrm{Liz}}$ & Reply & Liz \\
\hline 16 & Client & Reply & $\begin{array}{l}\text { Best wishes, } \\
\text { Hai }\end{array}$ \\
\hline 17 & Liz & Reply & Liz \\
\hline 18 & Client & Reply & $\mathrm{Hai}$ \\
\hline 19 & Client & String & $\mathrm{Hai}$ \\
\hline 20 & Client & String & NO SIGN-OFF \\
\hline 21 & Client & String & $\mathrm{Hai}$ \\
\hline 22 & Liz & Reply & $\begin{array}{l}\text { See you soon, } \\
\text { Liz }\end{array}$ \\
\hline 23 & Client & Reply & $\begin{array}{l}\text { See you soon! } \\
\text { Hai }\end{array}$ \\
\hline 24 & Liz & Reply & Liz \\
\hline 25 & Client & Reply & NO SIGN-OFF \\
\hline 26 & Liz & Reply & Liz \\
\hline 27 & Liz & String & NO SIGN-OFF \\
\hline 28 & Client & Reply & $\begin{array}{l}\text { Best wishes, } \\
\text { Hai }\end{array}$ \\
\hline 29 & Liz & Reply & $\begin{array}{l}\text { All the best, } \\
\text { Liz }\end{array}$ \\
\hline 30 & Client & Reply & $\begin{array}{l}\text { Best wishes, } \\
\mathrm{Hai}\end{array}$ \\
\hline
\end{tabular}

\begin{tabular}{|c|c|c|c|}
\hline 31 & Liz & Reply & $\begin{array}{l}\text { Best wishes, } \\
\text { Liz }\end{array}$ \\
\hline 32 & Client & Reply & $\mathrm{Hai}$ \\
\hline 33 & Client & String & $\begin{array}{l}\text { Best wishes, } \\
\text { Hai }\end{array}$ \\
\hline 34 & Liz & Reply & Liz \\
\hline 35 & Client & Reply & $\begin{array}{l}\text { Hope you get } \\
\text { better soon! } \\
\text { Hai }\end{array}$ \\
\hline 36 & Liz & Reply & $\begin{array}{l}\text { All the best, } \\
\text { Liz }\end{array}$ \\
\hline 37 & Client & Reply & Hai \\
\hline 38 & Liz & Reply & Liz \\
\hline 39 & Client & Reply & Hai \\
\hline 40 & Client & String & $\begin{array}{l}\text { Best wishes, } \\
\mathrm{Hai}\end{array}$ \\
\hline 41 & Client & String & $\begin{array}{l}\text { Best wishes, } \\
\mathrm{Hai}\end{array}$ \\
\hline 42 & Liz & Reply & $\begin{array}{l}\text { All the best, } \\
\text { Liz }\end{array}$ \\
\hline 43 & Liz & String & Liz \\
\hline 44 & Client & Reply & $\mathrm{Hai}$ \\
\hline 45 & Liz & Reply & $\begin{array}{l}\text { Good luck with } \\
\text { the hand in, } \\
\text { Liz }\end{array}$ \\
\hline 46 & Client & Reply & $\begin{array}{l}\text { Best wishes, } \\
\text { Hai }\end{array}$ \\
\hline 47 & Liz & Reply & $\begin{array}{l}\text { Best wishes, } \\
\text { Liz }\end{array}$ \\
\hline 48 & Client & Reply & Hai \\
\hline 49 & Client & String & $\begin{array}{l}\text { Best wishes, } \\
\mathrm{Hai}\end{array}$ \\
\hline 50 & Liz & Reply & $\begin{array}{l}\text { Have a great } \\
\text { weekend, } \\
\text { Liz }\end{array}$ \\
\hline 51 & Liz & String & $\begin{array}{l}\text { All the best, } \\
\text { Liz }\end{array}$ \\
\hline 52 & Client & Reply & $\begin{array}{l}\text { Best wishes, } \\
\text { Hai }\end{array}$ \\
\hline 53 & Liz & Reply & $\begin{array}{l}\text { Best wishes, } \\
\text { Liz }\end{array}$ \\
\hline 54 & Client & Reply & $\begin{array}{l}\text { Best wishes, } \\
\text { Hai }\end{array}$ \\
\hline 55 & $\overline{\text { Liz }}$ & Reply & $\mathrm{Xx}: \mathrm{D}$ \\
\hline
\end{tabular}

